\title{
Hyperoxia and Apoptosis in Developing Mouse Lung Mesenchyme
}

\author{
HEATHER I. DIEPERINK, TIMOTHY S. BLACKWELL, AND LAWRENCE S. PRINCE
}

Departments of Pediatrics, Cell Biology, and Physiology and Biophysics [H.I.D., L.S.P.], University of Alabama at Birmingham, Birmingham, AL 35294; Departments of Medicine, Cell and Developmental Biology, and Cancer Biology [T.S.B.], Vanderbilt University

School of Medicine, Nashville, TN 37232

\begin{abstract}
Hyperoxia contributes to the development of bronchopulmonary dysplasia in former premature infants. Injurious environmental factors such as hyperoxia may disrupt distal airway branching and alveolar septation, as these critical stages in lung development occur following birth in extremely premature infants. To test if hyperoxia directly inhibited distal airway branching, we cultured E16 fetal mouse lung explants in either $20 \%$ (control) or 95\% oxygen (hyperoxia). Hyperoxia reduced the number of distal airways to less than $50 \%$ of controls. Explants cultured in $95 \%$ oxygen also had fewer complex distal airways compared with controls. Mesenchymal cells adjacent to distal airways in hyperoxic explants appeared apoptotic by phase microscopy. Consistent with increased apoptosis, explants cultured in hyperoxia had increased caspase 3/7 activity compared with controls. Hyperoxia also increased mesenchymal caspase 3 expression and annexin $\mathrm{V}$ binding within cultured explants as visualized by fluorescence microscopy. We measured increased annexin $\mathrm{V}$ binding in isolated primary fetal lung mesenchymal cells cultured in $95 \%$ oxygen suggesting a direct effect on cells within the mesenchyme. Hyperoxia can lead to NF- $\kappa \mathrm{B}$ activation, which mediates inflammatory cascades and may protect cells from apoptosis. We detected NF- $\kappa \mathrm{B}$ activation and nuclear p65 localization in explants exposed to $48 \mathrm{~h}$ of hyperoxia. Inhibition of NF- $\kappa \mathrm{B}$ prevented the hyperoxia-induced activation of caspase $3 . N F-\kappa B$ activation may therefore contribute to apoptosis in the developing fetal mouse lung following hyperoxia exposure. Our data suggest hyperoxia inhibits distal airway branching and directly induces apoptosis of the fetal mouse lung mesenchyme. (Pediatr Res 59: 185-190, 2006)
\end{abstract}

$\mathrm{B}$ ranching of distal airway saccules into immature alveoli begins in the canalicular phase of human fetal lung development at 20-22 wk gestation, equivalent to embryonal day 16 (E16) in mice (1-4). As the fetal lung progresses from the canalicular to alveolar phase of development (30 wk gestation in humans, E18 in mice), mesenchymal cells adja-

Received April 14, 2005; accepted August 18, 2005.

Correspondence: Lawrence S. Prince, M.D., Ph.D., Assistant Professor of Pediatrics, Division of Neonatology, Volker Hall 648C, 1670 University Boulevard, University of Alabama at Birmingham, Birmingham, AL 35294; e-mail: lprince@ peds.uab.edu

Research supported by a NHLBI T35 (HL07473) (HID), The Parker Francis Families Foundation, the Child Health Research Center (NICHD43397) and Research Institute of the Children's Hospital of Alabama (LSP), and NIH grants HL61419 and HL66196 (TSB). This work was performed in a facility constructed with support from Research Facilities Improvement Program Grant No. C06 RR 15490 from the National Center for Research Resources, National Institutes of Health.

DOI: $10.1203 / 01$. pdr.0000196371.85945.3a cent airways undergo apoptosis, allowing formation of thin interstitial septae (5). Alveoli then continue to divide and septate following birth. Extremely premature infants delivered between 23-27 wk are therefore born before distal lung branching is complete and before alveolarization begins. Abnormal distal airway branching and dysregulated mesenchymal apoptosis in these premature infants may contribute to the pathogenesis of bronchopulmonary dysplasia(6).

The lungs of infants with bronchopulmonary dysplasia contain large, simplified alveolar structures (6). With this pathology, the surface area for gas exchange is reduced and the lungs are prone to heterogeneous patterns of atelectasis and hyperinflation. Both arrested lung development and lung injury contribute to the pathogenesis of bronchopulmonary dysplasia (7). In addition to contributing to lung injury, hyperoxia inhibits normal alveolar development in rodents $(8-$ 10). Alveolarization takes place following birth in mice and rats; newborn rodent lungs resemble the human lung at approximately 30-32 wk gestation. By exposing newborn rodents to hyperoxia, investigators have studied how increased oxygen levels can disrupt alveolar development. These studies suggest hyperoxia contributes to the abnormal alveolar development in bronchopulmonary dysplasia.

Newborn rats and mice exposed to hyperoxia following birth develop fewer, larger alveoli, similar to the lungs of premature infants with bronchopulmonary dysplasia (8-10). However, extremely premature infants are exposed to hyperoxia before alveolar development. We were interested in how hyperoxia might affect earlier stages of distal airway development. We hypothesized that hyperoxia might directly inhibit distal lung branching at the canalicular stage (20-27 wk in humans, E15-17 in mice). Epithelial-mesenchymal interactions unique to this stage of development may be a potential target of hyperoxia. To study this stage of fetal lung development in mice, we have developed a fetal lung explant model (11). E16 fetal mouse lung explants develop in culture similarly to 23-25 wk human lungs, with branching of terminal saccules and differentiation of alveolar epithelial cells into type I and type II epithelia. Cultured explants also develop in the absence of systemic fetal or maternal influences. We

Abbreviations: CCD, charge-coupled device; DAPI, 4'-6-Diamidino-2-phenylindole 
therefore used this fetal mouse lung explant model to study the direct effects of hyperoxia on distal airway branching.

\section{MATERIALS AND METHODS}

Animals and tissue culture. All studies were approved by the Institutional Animal Care and Use Committee at the University of Alabama at Birmingham. BALBc/J mice were obtained from Jackson Laboratories. HLL transgenic mice contain the luciferase reporter gene downstream of a NF- $\kappa \mathrm{B}$ response element and have been described previously (12-14). Timed matings were performed, with embryonal day zero (E0) defined as the day of vaginal plug. On E16, pregnant females were euthanized and fetal lungs were isolated and dissected free of surrounding tissues. For explant culture, fetal lungs were minced into $0.5-1 \mathrm{~mm}^{3}$ pieces using sterile technique under a stereomicroscope (11). The explants were then cultured on permeable supports (Transwell, Costar). For gas-liquid interface cultures, serum-free Dulbecco's Modification of Eagle's Medium (DMEM) was placed in the basal compartment, allowing diffusion of nutrients through the membrane to the explants. Culturing the explants in a gas-liquid interface allowed exposure to atmospheric gas concentrations without the barrier to oxygen diffusion present in submerged culture. Explants were cultured at $37^{\circ} \mathrm{C}$ in a humidified atmosphere of $5 \% \mathrm{CO}_{2}$ and either $95 \%$ air (control) or $95 \%$ oxygen (hyperoxia) for up to $72 \mathrm{~h}$.

Primary fetal lung mesenchymal cells were isolated by allowing slices of E16 fetal mouse lungs to attach to tissue culture-treated plastic dishes in DMEM containing 10\% fetal bovine serum. Following outgrowth of mesenchymal cells from the explant, the explants were manually removed under microscopic visualization. The mesenchymal cells remaining on the dishes were cultured in serum-free DMEM and subcultured using EDTA to release them from the plastic surface. Cells were typically passaged no more than five times.

DNA laddering. E16 fetal mouse lung explants from BALBc/J mice were cultured for $48 \mathrm{~h}$ in either $20 \%$ or $95 \%$ oxygen. The explants were then homogenized in nucleic acid binding buffer $(6 \mathrm{M}$ guanidine- $\mathrm{HCl}, 10 \mathrm{mM}$ urea, $10 \mathrm{mM}$ Tris-HCl, $20 \%$ Triton X-100, pH 4.4). DNA was bound to glass fiber spin columns (Apoptotic DNA Ladder Kit, Roche Applied Science) and eluted with $10 \mathrm{mM}$ Tris $(\mathrm{pH} 8.5)$. Eluted samples were separated by horizontal electrophoresis using $1 \%$ agarose gels. Camptothecin-treated U937 cells were supplied by the manufacturer as a positive control for DNA laddering.

Annexin V binding. For fluorescent labeling of apoptotic cells within fetal lung explants and in cultures of fetal lung mesenchymal cells, we used the Vybrant Apoptosis Assay Kit (Molecular Probes, Burlingame, CA). Explants or cultured mesenchymal cells were washed with PBS and then with annexinbinding buffer (10 mM HEPES, $140 \mathrm{mM} \mathrm{NaCl}, 2.5 \mathrm{mM} \mathrm{CaCl}_{2}, \mathrm{pH}$ 7.4). Biotinylated annexin $\mathrm{V}$ was added to the explants and incubated for $15 \mathrm{~min}$ at room temperature. Following washes with annexin-binding buffer, annexin V was detected with streptavidin-conjugated Alexa Fluor 350 (Molecular Probes). Necrotic and late apoptotic cells were labeled by adding propidium iodide ( $1 \mu \mathrm{g} / \mathrm{mL}$ in annexin-binding buffer). Explants and cells were imaged using an inverted fluorescence microscope (Axiovert 25, Zeiss, Germany) with a CCD camera (Qimaging). Cultured mesenchymal cells labeled with either annexin $\mathrm{V}$ or propidium iodide were counted using Histometrix software (Andor Bioimaging).

Caspase assay. E16 mouse lung explants were cultured in either $20 \% \mathrm{O}_{2}$ or $95 \% \mathrm{O}_{2}$ and homogenized in PBS containing TritonX-100 (0.5\%) and protease inhibitors. Caspase 3/7 activity in explant lysates was measured using an in vitro luciferase assay (Caspase-Glo, Promega, Madison, WI). Lysates were incubated with a luciferase substrate conjugated to an aspartic acid-glutamic acid-valine-aspartic acid (DEVD) fusion peptide, a target sequence for caspase $3 / 7$. Upon cleavage by caspase $3 / 7$, the substrate was then available to react with exogenously added luciferase. Light units were measured in a single-tube luminometer (Turner Biosystems). Four explants were used at each time point and condition, and each lysate was measured in triplicate. Light units were normalized to protein concentration in each lysate as measured using the BCA method (Pierce, Rockford, IL). A similar protocol was used to measure caspase $3 / 7$ activity in mesenchymal cells cultured in either $20 \%$ or $95 \%$ oxygen, $250 \mathrm{ng} / \mathrm{mL}$ E. coli lipopolysaccharide (Sigma Chemical Co.), or $1 \mu \mathrm{M}$ parthenolide (Calbiochem).

Antibodies and immunomicroscopy. Polyclonal antibodies against caspase 3, vimentin, and p65 were obtained from Santa Cruz Biotechnology. For immunolabeling in fetal lung explants, intact fetal lung explants were fixed in $4 \%$ paraformaldehyde and permeabilized with $0.2 \%$ Triton X-100. Nonspecific binding was reduced with SuperBlock (Pierce). Primary antibodies were incubated with the explants overnight at $4^{\circ} \mathrm{C}$. Following washing, Alexa594 or Alexa633-conjugated secondary antibodies were bound at room temperature. The explants were then treated with SYTO13 or DAPI (both from Molecular Probes) for nuclear labeling and mounted between glass slides and $0.17 \mathrm{~mm}$ coverslips using Vectashield anti-fade aqueous mounting media. The explants were not removed from their permeable supports for labeling or imaging. Confocal images were obtained using a Leica DMIRB laser-scanning confocal microscope. For detecting p65 nuclear localization, monochromatic images of 4'-6-diamidino-2-phenylindole (DAPI)-stained nuclei and Alexa594 labeled antibodies were merged. Overlapping red and blue fluorescence appears magenta. Fluorescent red signal that did not overlap with blue fluorescence was pseudocolored yellow using Photoshop (Adobe). Acquisition and processing of control and hyperoxia images were performed using identical settings and procedures.

Image analysis and statistics. Brightfield images of fetal lung explants were obtained using an inverted Axiovert 25 microscope with a color chargecoupled device (CCD) camera (Q Imaging). Images were saved as either TIFF or high-quality JPEG files and imported into Histometrix (Andor Bioimaging) for analysis of peripheral branch number. For branch complexity, the distal airways were mapped in Photoshop and imported into Image (Scion). The background image was removed by using the threshold function. The mapped airways were converted to binary mode and then skeletonized for complexity analysis. The percentage of airway branches that underwent multiple generations of branching was calculated for each image. All statistical data were exported into Excel spreadsheets (Microsoft). Data are presented as mean \pm SEM. Unpaired $t$-tests were performed for statistical comparisons.

$\boldsymbol{N F}$ - $\boldsymbol{\kappa} \boldsymbol{B}$ activation in HLL mice. E16 fetal lung explants from HLL mice were cultured in $20 \%$ or $95 \%$ oxygen. An additional set of explants was cultured in $20 \%$ oxygen in the presence of $250 \mathrm{ng} / \mathrm{mL}$ LPS (E. coli O55:B5; Sigma Chemical Co.). Luciferase activity was measured at $4 \mathrm{~h}, 24$, and $48 \mathrm{~h}$ using firefly luciferase (Steady-Glo, Promega) and a single tube luminometer. Total protein concentrations in explant lysates were measured using the BCA method (Pierce). Nine explants were measured in triplicate for each condition and time point. Luciferase activity (light units/mg protein) was normalized to control lysates at each time point.

\section{RESULTS}

To study the effects of hyperoxia on distal airway branching in the fetal mouse lung, we cultured E16 fetal lung explants on gas-liquid interfaces. Serum-free media was placed beneath a permeable membrane supporting the explants, which were cultured in humidified atmospheres containing oxygen concentrations of either 20\% (control) or 95\% (hyperoxia). Structural development of the explants was visualized by light microscopy. Following $72 \mathrm{~h}$ of culture, the distal airways in control explants branched and divided into more complex structures (Fig. 1A). The airways of explants cultured in $95 \%$ oxygen (Fig. $1 B$ ) were larger with fewer branches along the explant periphery compared with controls (Fig. 1C).

To account for potential effects of hyperoxia on generalized explant growth, we normalized the number of distal airways formed along the explant periphery to total explant area (Fig. $1 D)$. Airway branching occurred in control explants as the explants grew in size, keeping the number of branches per area relatively constant. However, explants cultured in $95 \%$ oxygen had fewer branching events as the explants grew, decreasing the number of airways per $\mathrm{mm}^{2}$. The distal airway branching pattern of hyperoxia-exposed explants also appeared more simplified than controls. Using a digital mapping technique, we calculated that airways in explants cultured in $95 \%$ oxygen had fewer complex airways than controls (Fig. 2G). These observations suggested that hyperoxia could alter the structural development of the distal airways in fetal mouse lung explants.

Hyperoxia reduced the amount of visible mesenchyme adjacent to the distal airways (Figs. $1 A, B ; 2 A, D$ ). We hypothesized that increased oxygen concentration could lead to mesenchymal apoptosis and cell loss within fetal lung ex- 


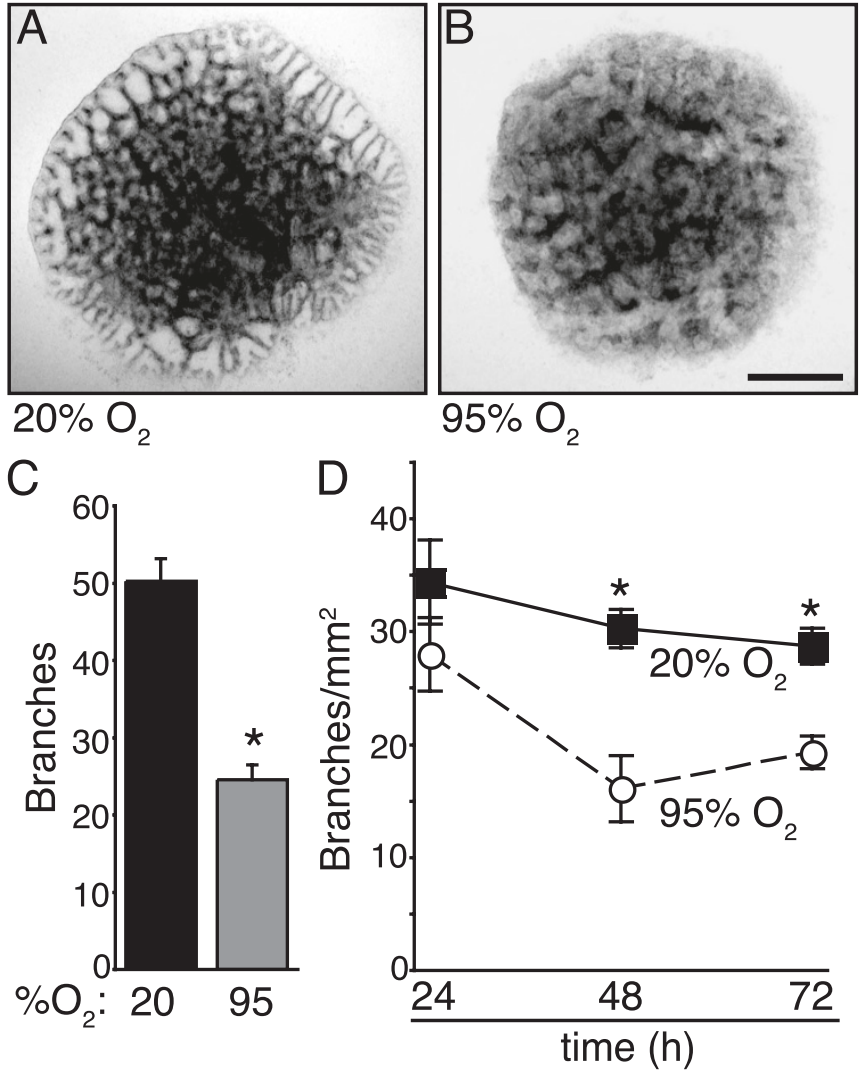

Figure 1. Hyperoxia inhibited distal airway branching. E16 fetal mouse lung explants were cultured in 20\% (control) or 95\% (hyperoxia) oxygen. (A) Low-power brightfield photomicrograph of control explant cultured for $72 \mathrm{~h}$. Branching of the distal airways can be seen along the periphery of the explant. (B) Low-power brightfield photomicrograph of an explant cultured for $72 \mathrm{~h}$ in hyperoxia. Distal airways were larger with decreased branching (Bar $=500$ $\mu \mathrm{M}) .(C)$ The number of distal airway branches along the periphery of control explants was higher than hyperoxia-exposed explants at $72 \mathrm{~h}(* p<0.01 ; n$ $=9$ ). $(D)$ Hyperoxia inhibited the number of distal airway branches per area in cultured explants. Brightfield images of control and hyperoxia-exposed explants were obtained at $24 \mathrm{~h}, 48 \mathrm{~h}$, and $72 \mathrm{~h}$. The number of distal airway branches along the periphery of each explant was normalized to explant area using Histometrix software. In control explants, branches formed as the explant grew. Hyperoxia inhibited airway branching more than explant growth, causing a decrease in the number of branches $/ \mathrm{mm}^{2}$ at $48 \mathrm{~h}$ and $72 \mathrm{~h}$ $(* p<0.01 ; n=9)$.

plants. To initially test this hypothesis, we measured DNA laddering in fetal lung explants cultured in 95\% oxygen. During apoptosis, cellular DNA is cleaved into internucleosomal fragments, producing a laddering pattern on agarose gels. Figure $3 A$ shows increased laddering of DNA in explants cultured in $95 \%$ oxygen compared with $20 \%$ oxygen, consistent with increased apoptosis. We next measured the effect of 95\% oxygen on caspase 3 activity. Caspase 3 is a cysteine protease whose expression and activity induces apoptosis (15). Using a luminescent caspase 3 substrate, we measured increased caspase 3 activity in fetal lung explant homogenates cultured for $48 \mathrm{~h}$ and $72 \mathrm{~h}$ in $95 \%$ oxygen (Fig. $3 B$ ). These findings supported increased apoptosis following exposure to hyperoxia.

To measure and localize cellular apoptosis in live fetal lung explants, we briefly incubated explants with recombinant,
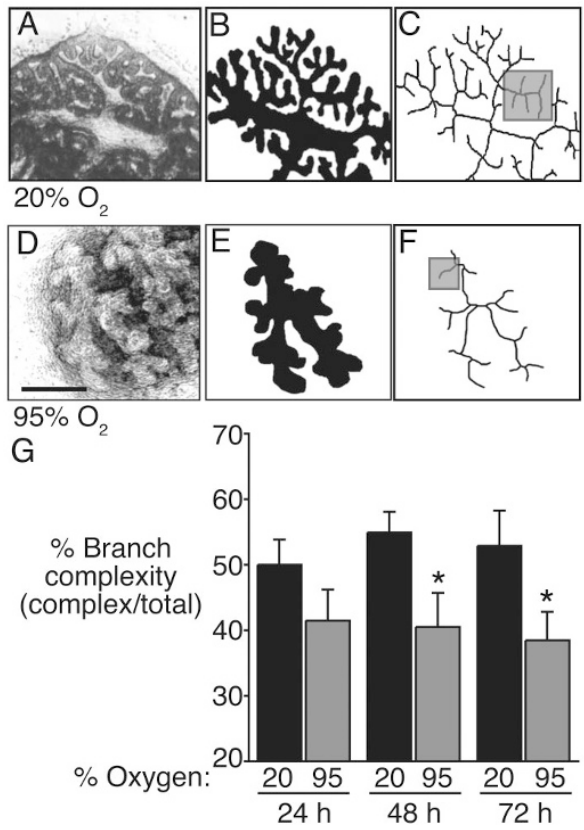

Figure 2. Hyperoxia inhibited complexity of branching distal airways. Phase micrographs of control $(A-C)$ and hyperoxia-exposed $(D-F)$ explants were analyzed as in the Materials and Methods $(\mathrm{Bar}=250 \mu \mathrm{M})$. Distal airways identified in brightfield images $(A, D)$ were mapped in Photoshop $(B, E)$. The airways were then skeletonized in Image $(C, F)$. The shaded boxes in $(C)$ and $(F)$ illustrate complex $(C)$ and noncomplex $(F)$ distal airway branches. $(G)$. Hyperoxia decreased the percentage of complex distal airway branches at $48 \mathrm{~h}$ and $72 \mathrm{~h}$ of culture ( ${ }^{*} p<0.05 ; n=8-13$ for each time point and condition).

biotinylated annexin $\mathrm{V}$, which binds phosphatidylserine in cell surface membranes. Phosphatidylserine is normally restricted to the inner leaflet of the plasma membrane, but can appear on the cell surface when cells become necrotic or apoptotic (16). Using fluorescent avidin for detection, we visualized increased annexin $\mathrm{V}$ binding in explants cultured in 95\% oxygen (Fig. $3 C, D$ ). Propidium iodide-labeled necrotic cells and late apoptotic cells were rare in both conditions (not shown). We then examined caspase 3 immunostaining in whole mount explants by confocal microscopy. Explants cultured in 95\% oxygen had increased caspase 3 immunostaining at the explant margins (Fig. 3E, F). To better determine the cellular sites of caspase 3 expression, we labeled explants with antibodies against caspase 3 and the mesenchymal cell marker vimentin (Fig. $3 G-L$ ). Caspase 3 immunostaining was primarily in cells adjacent to distal airways and co-localized with anti-vimentin labeling. Increased oxygen concentrations therefore led to the accumulation of apoptotic cells within the fetal lung mesenchyme.

To test if hyperoxia could directly stimulate apoptosis in isolated fetal lung mesenchymal cells, we cultured primary mesenchymal cells in $20 \%$ or $95 \%$ oxygen. Compared with cells in $20 \%$ oxygen, cultures maintained in $95 \%$ oxygen contained increased numbers of rounded cells when visualized by phase microscopy, consistent with apoptosis (Fig. 4B, D). We identified these rounded cells as apoptotic by annexin $\mathrm{V}$ labeling (Fig. 4E, F). In control cultures, annexin V labeled approximately $15 \%$ of the cells. Of these cells, $6 \%$ also accumulated propidium iodide, representing late apoptotic or 

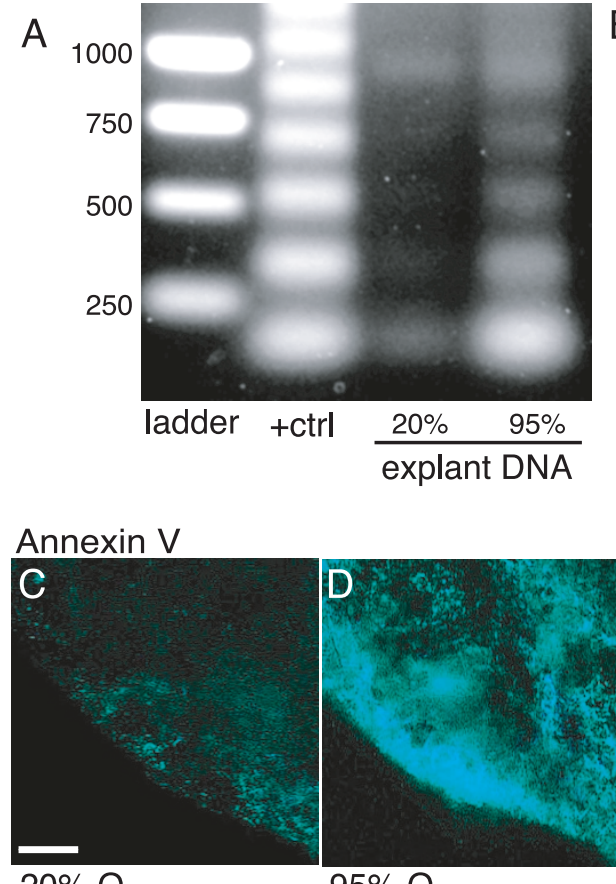

$20 \% \mathrm{O}_{2}$

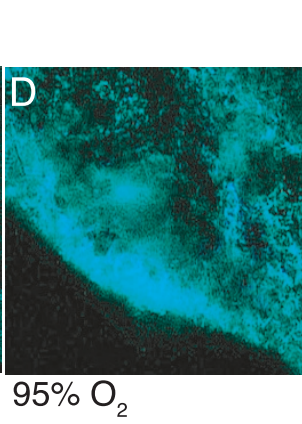

Caspase 3

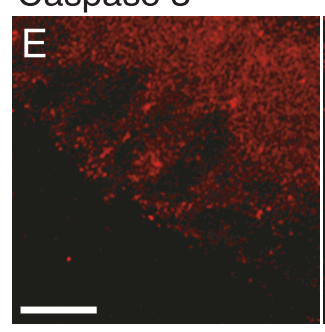

$20 \% \mathrm{O}_{2}$

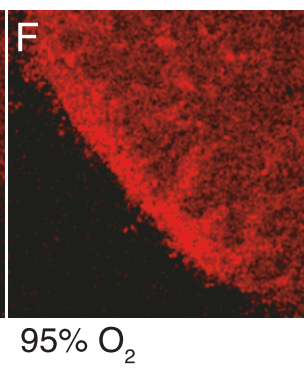

$95 \% \mathrm{O}_{2}$
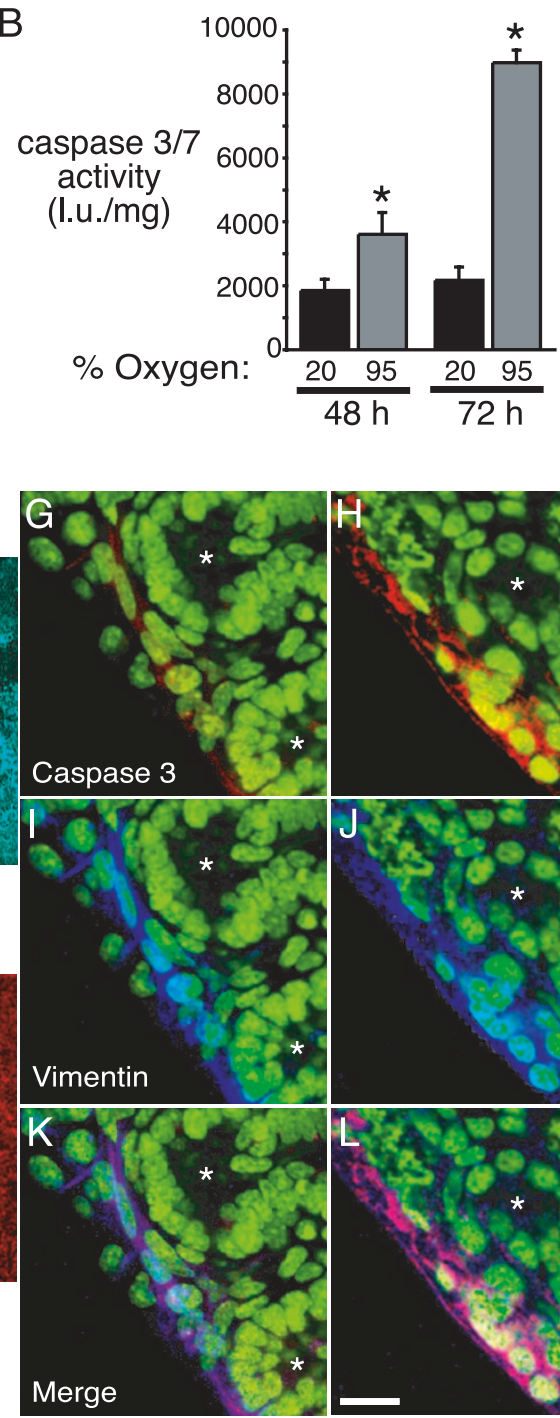

$20 \% \mathrm{O}_{2}$

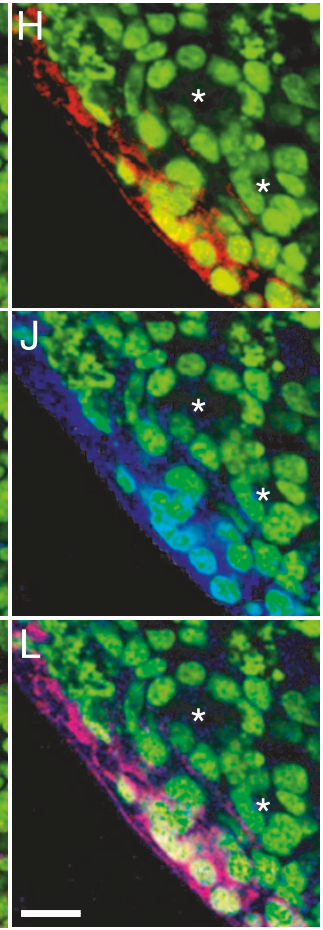

$95 \% \mathrm{O}_{2}$
Figure 3. Hyperoxia increased mesenchymal apoptosis. (A). E16 fetal lung explants were cultured in $20 \%$ or $95 \%$ oxygen for $48 \mathrm{~h}$. Nucleosomal DNA was isolated and separated on a $1 \%$ agarose gel. Camptothecin-treated U937 cells were used as a positive control for apoptotic DNA laddering $(+\mathrm{ctrl}) .(B)$. E16 fetal lung explants were cultured in $20 \%$ or $95 \%$ oxygen for $48 \mathrm{~h}$ or $72 \mathrm{~h}$. Explants were then homogenized and caspase 3 activity was measured using a luminescence assay $(* p<0.05$; $n=4)(C, D)$. Annexin V binding in fetal mouse lung explants. E16 explants were cultured in $20 \%(C)$ or $95 \%(D)$ oxygen for $72 \mathrm{~h}$. The explants were then incubated with biotinylated annexin $\mathrm{V}$, which was visualized using Alexa350 streptavidin and fluorescence microscopy. Representative images are shown $(B a r=100 \mu \mathrm{m})(E, F)$. Explants cultured in $20 \%$ or $95 \%$ oxygen for $72 \mathrm{~h}$ were fixed and stained with a polyclonal antibody against caspase 3 . Staining was visualized by laser-scanning confocal microscopy. Caspase 3 immunostaining was seen in the interstitial and mesenchymal regions of explants treated with $95 \%$ oxygen. Representative images are shown $(\mathrm{Bar}=200 \mu \mathrm{m})(G-L)$. Caspase 3 immunostaining in fetal lung mesenchyme. Fetal mouse lung explants cultured for $72 \mathrm{~h}$ in $20 \%(G, I, K)$ or $95 \%(H, J, L)$ oxygen were labeled with antibodies against caspase 3 (red) and vimentin (blue) and visualized by confocal microscopy. Nuclei were labeled with SYTO13. In each panel, the airway lumen is identified by an asterisk (*). Caspase 3 immunostaining colocalized with the mesenchymal marker vimentin $(\mathrm{Bar}=10 \mu \mathrm{m})$. necrotic cells. Annexin V labeled 40\% of mesenchymal cells in hyperoxic cultures, with no increase in the percentage of cells labeling with propidium iodide. These measurements suggested hyperoxia directly stimulated apoptosis in cultured fetal lung mesenchymal cells.

Hyperoxia promotes reactive oxygen species formation, inducing the activation and nuclear translocation of NF- $\kappa \mathrm{B}$ (17). We hypothesized that NF- $\kappa \mathrm{B}$ activation in fetal lung explants exposed to hyperoxia contributed to cellular apoptosis. To visualize the cellular sites of NF- $\kappa \mathrm{B}$ activation in explants, we localized the p65 subunit of NF- $\kappa \mathrm{B}$ in control and hyperoxia-exposed BALBc/J fetal lung explants by confocal microscopy. Explants were fixed for immunostaining at $48 \mathrm{~h}$ of culture. In control explants, p65 localized to the cytoplasm (Fig. 5A). In explants exposed to 95\% oxygen, nuclear staining for p65 was detected, consistent with NF- $\kappa$ B activation (Fig. 5B). Not all cells in the hyperoxia-exposed explants displayed p65 nuclear staining, and nuclear localization was detected in cells both within the mesenchyme and lining the distal airways. We next tested if hyperoxia activated $\mathrm{NF}-\kappa \mathrm{B}$ transcriptional activity in fetal mouse lung explants from HLL luciferase transgenic reporter mice (12-14). Explants were cultured in either $20 \%$ or $95 \%$ oxygen and luciferase activity was measured in homogenates. As a control, we also treated explants with $E$. coli lipopolysaccharide, which activates NF- $\kappa$ B through the TLR4 pathway (18). Lipopolysaccharide increased luciferase activity at $24 \mathrm{~h}$, with return to baseline by $48 \mathrm{~h}$ (Fig. 5C). Hyperoxia-exposed explants expressed increased luciferase activity at $48 \mathrm{~h}$ of culture, consistent with NF- $\kappa \mathrm{B}$ activation.

We then tested if activation or inhibition of NF- $\kappa$ B altered caspase 3 activity in cultured fetal lung mesenchymal cells. Culturing cells in $95 \%$ oxygen increased caspase 3 activity (Fig. 5D) as we observed earlier in cultured explants (see Fig. $3 B$ ). Addition of the NF- $\kappa$ B inhibitor parthenolide (19) to the media slightly decreased baseline caspase 3 activity, and inhibited the increase in caspase 3 activity seen with exposure to $95 \%$ oxygen. Activation of NF- $\kappa \mathrm{B}$ with lipopolysaccharide also increased caspase 3 activity, but to a lesser degree compared with $95 \%$ oxygen. These data suggest that NF- $\kappa \mathrm{B}$ activation in fetal lung mesenchymal cells may play a role in hyperoxia-induced apoptosis. 

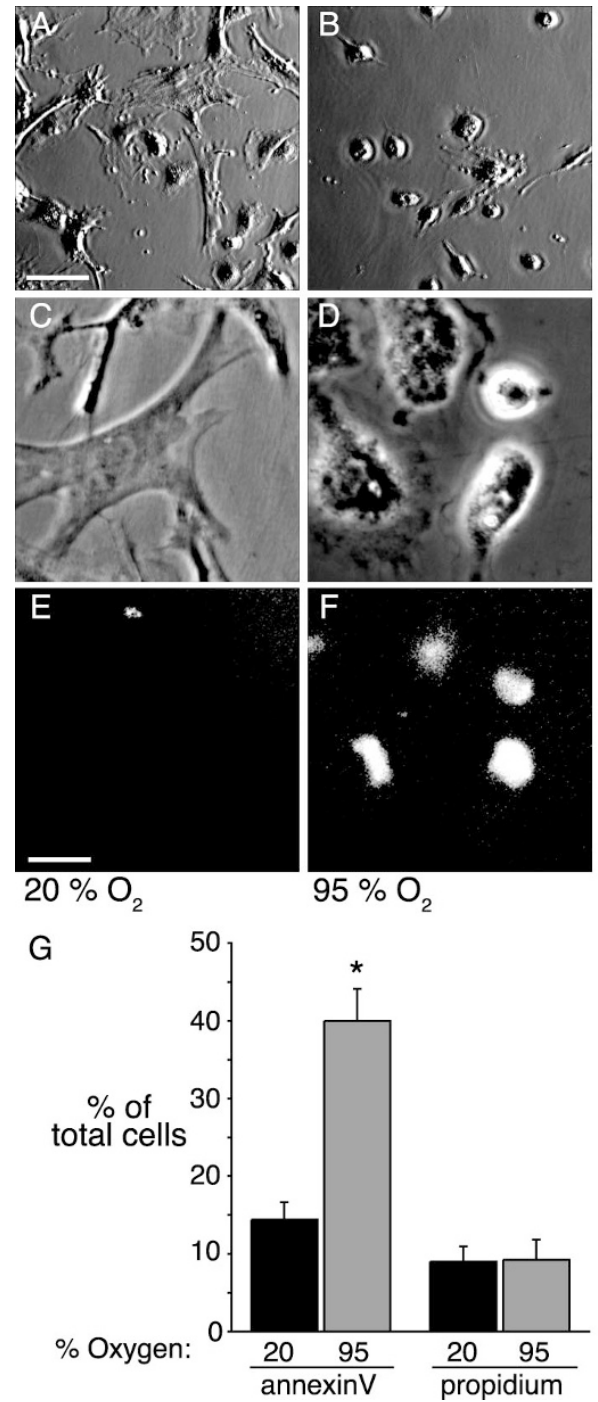

Figure 4. Apoptosis of primary fetal lung mesenchymal cells. Primary fetal lung mesenchyme was isolated from E16 mouse lungs and cultured in either $20 \%(A, C, E)$ or $95 \%(B, D, F)$ oxygen. Following $48 \mathrm{~h}$ of culture, many cells cultured in $95 \%$ oxygen appeared rounded, consistent with apoptosis. $(A, B)$. Low power Varel images of primary mesenchymal cells culture in $20 \%(A)$ or 95\% $(B)$ oxygen $(\mathrm{Bar}=25 \mu \mathrm{m})$. $(C, D)$. Phase contrast images. $(E, F)$. Fluorescence images of the same cells in $(C)$ and $(D)$ labeled with fluorescent annexin V $($ Bar $=10 \mu \mathrm{m})$. $(G)$. Percentage of cultured mesenchymal cells labeled with annexin $\mathrm{V}$ or propidium iodide. Culturing cells in $95 \%$ oxygen increased the number of cells labeling with annexin $\mathrm{V}$, consistent with apoptosis(* $p<0.01 ; n=10)$. No increase in cells accumulating propidium iodide was measured.

\section{DISCUSSION}

We have used a fetal mouse model of distal lung development to study the mechanisms by which hyperoxia inhibits alveolarization. Hyperoxia decreased peripheral airway number and airway branching complexity, processes guided by epithelial-mesenchymal interactions. By increasing mesenchymal cell apoptosis, hyperoxia targeted a region of the developing lung required for normal alveolar structure.

Exposure to hyperoxia during the critical stage of alveolarization alters structural lung development (20). Distal branching of terminal saccules into immature alveoli in E16 mouse lung explants parallels the structural development of a human fetal lung from 20-27 wk gestation (1-4). By using this
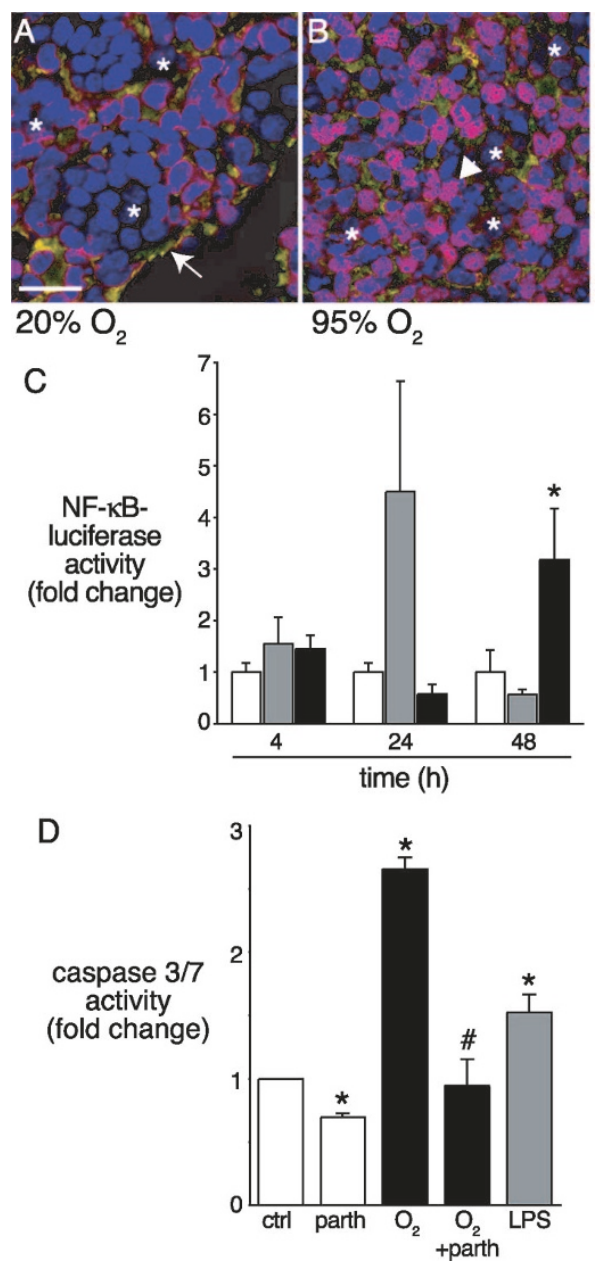

Figure 5. NF- $\kappa \mathrm{B}$ activation in fetal lung explants $(A, B)$. Immunolocalization of p65 in fetal lung explants. Explants were cultured in either 20\% (A) or 95\% (B) oxygen for $48 \mathrm{~h}$, fixed, and labeled with a polyclonal antibody against the p65 subunit of NF- $\kappa$ B. Labeling was detected using Alexa594 secondary antibodies. Nuclei were stained with DAPI. Explants were then imaged using a laser-scanning confocal microscope. Staining for p65 that overlaps with nuclei is magenta (arrowhead), whereas p65 staining in the cytoplasm is yellow (arrow). Distal airway lumina are indicated with asterisks $(*)$. Representative $63 \times$ images are shown $(\mathrm{Bar}=20 \mu \mathrm{m})(C)$. NF- $\kappa \mathrm{B}$ luciferase reporter expression. E16 HLL fetal mouse lung explants were cultured in $20 \%$ oxygen (white bars), $20 \%$ oxygen with E. coli lipopolysaccharide (250 $\mathrm{ng} / \mathrm{mL}$ ) in the media (grey bars), or in $95 \%$ oxygen (black bars). At $4 \mathrm{~h}, 24 \mathrm{~h}$, and $48 \mathrm{~h}$, explants were homogenized and luciferase activity was measured. Data were normalized to protein concentration and expressed as fold change over control. Hyperoxia increased luciferase activity only at $48 \mathrm{~h}$ of culture (* $p<0.05 ; n=6)(D)$. NF- $\kappa \mathrm{B}$ inhibition reduced caspase $3 / 7$ activity. Fetal lung mesenchymal cells were cultured for $48 \mathrm{~h}$ in $20 \%$ oxygen (ctrl), $95 \%$ oxygen $\left(\mathrm{O}_{2}\right)$, in media containing the NF- $\kappa \mathrm{B}$ inhibitor parthenolide $(1 \mu \mathrm{M}$; parth), or E. coli lipopolysaccharide (250 ng/mL; LPS). Caspase 3/7 activity was measured using a luminescence assay. Asterisks $(*)$ denote significant differences from control $(p<0.01 ; n=8)$. Parthenolide inhibited caspase 3/7 activity in cells cultured in $95 \%$ oxygen (\# $p<0.01 ; n=14$ ).

model, we can study alveolar development at an earlier stage than postnatal rodent models, which study later stages of alveolar septation and development.

In addition to measuring abnormal airway structure, we used our explant model to visualize hyperoxia-induced apoptosis of the fetal lung mesenchyme. Hyperoxia also led to apoptosis in cultured fetal mouse lung mesenchymal cells, suggesting a direct effect. Mesenchymal cells synthesize 
growth factors including FGF7 and FGF10 that are required for structural development of the lung $(21,22)$. Vascular structures also develop from within the mesenchyme to form the alveolar-capillary bed (23). Increased apoptosis of these important cells during a critical stage of lung development could therefore lead to abnormal alveolar formation.

Increased oxygen concentrations can lead to free radical formation and oxidation of amino acid residues on intracellular proteins. Oxidation of cysteine 179 on the alpha and beta subunits of I- $\kappa$ B kinase favors NF- $\kappa$ B activation. High levels of oxidative stress can also modify cysteine 62 on the p50 subunit of NF- $\kappa \mathrm{B}$ and alter DNA binding $(24,25)$. Therefore, the redox balance within cells can influence the NF- $\kappa \mathrm{B}$ signaling pathway.

NF- $\kappa$ B activation can either promote or inhibit apoptosis depending on cell type $(26,27)$. In our studies using primary fetal lung mesenchymal cells, NF- $\kappa \mathrm{B}$ activation appeared to increase caspase 3 activity, which can lead to apoptosis. One possible mechanism in our system could be the NF- $\kappa \mathrm{B}-$ dependent release of pro-apoptotic signals. Both hyperoxia and lipopolysaccharide can increase release of $\operatorname{TNF} \alpha(17,28)$, which can lead to apoptosis through a receptor-mediated pathway (29). Antibodies against TNF $\alpha$ inhibit hyperoxiainduced caspase 3 activity in rat type II epithelia (30). Hyperoxia-induced apoptosis may also contribute to the pathogenesis of Legionella pneumophila pneumonia (31). We have not yet been able to determine whether such an autocrine mechanism exists in our model.

While apoptosis appeared restricted to mesenchymal cells, NF- $\kappa$ B nuclear localization was detected in both mesenchymal and epithelial cells. We have previously shown that signaling through TLR4 and NF- $\kappa$ B can promote differentiation of fetal lung epithelial cells into type II epithelia (11). Hyperoxia and NF- $\kappa \mathrm{B}$ activation may therefore have different effects depending on cell type within the fetal lung. Not all cells in hyperoxia-treated explants displayed nuclear p65 localization. Because nuclear trafficking and localization of p65 appears to be dynamic and may oscillate (32), this finding may have represented a snapshot of a global process. Alternatively, distinct subpopulations of cells may undergo NF- $\kappa$ B activation following hyperoxic exposure. The capacity of cells within the developing lung to respond to such environmental stimuli could therefore influence postnatal lung development in extremely premature infants.

Acknowledgments. We especially thank Victor Okoh, Joanna Sabine, and Mark Browne for their assistance and helpful comments.

\section{REFERENCES}

1. Ten Have-Opbroek AA 1981 The development of the lung in mammals: an analysis of concepts and findings. Am J Anat 162:201-219

2. Ten Have-Opbroek AA 1991 Lung development in the mouse embryo. Exp Lung Res 17:111-130

3. Inselman LS, Mellins RB 1981 Growth and development of the lung. J Pediatr 98:1-15
4. Perl AK, Whitsett JA 1999 Molecular mechanisms controlling lung morphogenesis. Clin Genet 56:14-27

5. Kresch MJ, Christian C, Wu F, Hussain N 1998 Ontogeny of apoptosis during lung development. Pediatr Res 43:426-431

6. Coalson JJ 2003 Pathology of new bronchopulmonary dysplasia. Semin Neonatol 8:73-81

7. Jobe AH, Ikegami M 1998 Mechanisms initiating lung injury in the preterm. Early Hum Dev 53:81-94

8. Blanco LN, Frank L 1993 The formation of alveoli in rat lung during the third and fourth postnatal weeks: effect of hyperoxia, dexamethasone, and deferoxamine. Pediatr Res 34:334-340

9. Hosford GE, Fang X, Olson DM 2004 Hyperoxia decreases matrix metalloproteinase- 9 and increases tissue inhibitor of matrix metalloproteinase-1 protein in the newborn rat lung: association with arrested alveolarization. Pediatr Res 56:26-34

10. Warner BB, Stuart LA, Papes RA, Wispe JR 1998 Functional and pathological effects of prolonged hyperoxia in neonatal mice. Am J Physiol 275:L110-117

11. Prince LS, Okoh VO, Moninger TO, Matalon S 2004 Lipopolysaccharide increases alveolar type II cell number in fetal mouse lungs through Toll-like receptor 4 and NF-kappaB. Am J Physiol Lung Cell Mol Physiol 287:L999-1006

12. Blackwell TS, Yull FE, Chen CL, Venkatakrishnan A, Blackwell TR, Hicks DJ, Lancaster LH, Christman JW, Kerr LD 2000 Multiorgan nuclear factor kappa B activation in a transgenic mouse model of systemic inflammation. Am J Respir Crit Care Med 162:1095-1101

13. Sadikot RT, Jansen ED, Blackwell TR, Zoia O, Yull F, Christman JW, Blackwell TS 2001 High-dose dexamethasone accentuates nuclear factor-kappa b activation in endotoxin-treated mice. Am J Respir Crit Care Med 164:873-878

14. Yull FE, Han W, Jansen ED, Everhart MB, Sadikot RT, Christman JW, Blackwell TS 2003 Bioluminescent detection of endotoxin effects on HIV-1 LTR-driven transcription in vivo. J Histochem Cytochem 51:741-749

15. Salvesen GS, Dixit VM 1997 Caspases: intracellular signaling by proteolysis. Cell 91:443-446

16. Koopman G, Reutelingsperger CP, Kuijten GA, Keehnen RM, Pals ST, van Oers, MH 1994 Annexin V for flow cytometric detection of phosphatidylserine expression on B cells undergoing apoptosis. Blood 84:1415-1420

17. Shea LM, Beehler C, Schwartz M, Shenkar R, Tuder R, Abraham E 1996 Hyperoxia activates NF-kappaB and increases TNF-alpha and IFN-gamma gene expression in mouse pulmonary lymphocytes. J Immunol 157:3902-3908

18. Beutler B, Du X, Poltorak A 2001 Identification of Toll-like receptor 4 (Tlr4) as the sole conduit for LPS signal transduction: genetic and evolutionary studies. J Endotoxin Res 7:277-280

19. Prince LS, Dieperink HI, Okoh VO, Fierro-Perez GA, Lallone RL 2005 Toll-like receptor signaling inhibits structural development of the distal fetal mouse lung. Dev Dyn 233:553-561

20. Randell SH, Mercer RR, Young SL 1989 Postnatal growth of pulmonary acini and alveoli in normal and oxygen-exposed rats studied by serial section reconstructions. Am J Anat 186:55-68

21. Cardoso WV, Itoh A, Nogawa H, Mason I, Brody JS 1997 FGF-1 and FGF-7 induce distinct patterns of growth and differentiation in embryonic lung epithelium. Dev Dyn 208:398-405

22. Bellusci S, Grindley J, Emoto H, Itoh N, Hogan BL 1997 Fibroblast growth factor 10 (FGF10) and branching morphogenesis in the embryonic mouse lung. Development 124:4867-4878

23. Gebb SA, Shannon JM 2000 Tissue interactions mediate early events in pulmonary vasculogenesis. Dev Dyn 217:159-169

24. Nishi T, Shimizu N, Hiramoto M, Sato I, Yamaguchi Y, Hasegawa M, Aizawa S, Tanaka H, Kataoka K, Watanabe H, Handa H 2002 Spatial redox regulation of a critical cysteine residue of NF-kappa B in vivo. J Biol Chem 277:44548-44556

25. Kabe Y, Ando K, Hirao S, Yoshida M, Handa H 2005 Redox regulation of NF-kappaB activation: distinct redox regulation between the cytoplasm and the nucleus. Antioxid Redox Signal 7:395-403

26. Yang $\mathrm{CH}$, Murti A, Pfeffer LM 2005 Interferon induces NF-kappaB-inducing kinase/tumor necrosis factor receptor-associated factor-dependent NF-kappaB activation to promote cell survival. J Biol Chem 280:31530-31536

27. Farhana L, Dawson MI, Fontana JA 2005 Apoptosis induction by a novel retinoidrelated molecule requires nuclear factor-kappaB activation. Cancer Res 65:49094917

28. Mathison J, Tobias P, Wolfson E, Ulevitch R 1991 Regulatory mechanisms of host responsiveness to endotoxin (lipopolysaccharide). Pathobiology 59:185-188

29. Chen G, Goeddel DV 2002 TNF-R1 signaling: a beautiful pathway. Science 296:1634-1635

30. Guthmann F, Wissel H, Schachtrup C, Tolle A, Rudiger M, Spener F, Rustow B 2005 Inhibition of TNFalpha in vivo prevents hyperoxia-mediated activation of caspase 3 in type II cells. Respir Res 6:10-

31. Tateda K, Deng JC, Moore TA, Newstead MW, Paine R 3rd, Kobayashi, N, Yamaguchi K, Standiford TJ 2003 Hyperoxia mediates acute lung injury and increased lethality in murine Legionella pneumonia: the role of apoptosis. J Immunol 170:4209-4216

32. Fagerlund R, Kinnunen L, Kohler M, Julkunen I, Melen K 2005 NF-\{kappa\}B is transported into the nucleus by importin \{alpha\} 3 and importin \{alpha\}4. J Biol Chem 280:15942-15951 